\title{
IN VITRO PLANT REGENERATION OF PAULOWNIA TOMENTOSA (THUNB.) STEUD. FROM SHOOT TIP AND LEAF SEGMENT
}

\author{
PK RoY \\ Plant Biotechnology and Genetic Engineering Division, Institute of Food and Radiation Biology, \\ Atomic Energy Research Establishment, G.P.O Box No-3787, Dhaka-1000, Bangladesh
}

Key words: In vitro culture, Explants, Acclimatization, Regeneration, Paulownia tomentosa

\begin{abstract}
An efficient protocol was developed for in vitro mass propagation of Paulownia tomentosa (Thunb.) Steud. using shoot tip and leaf segment explants from field grown plant. Different concentrations and combinations of BAP, Kn, zeatin and NAA were used for multiple shoot regeneration. Among two types of explants, leaf segment produced the highest number of shoots per explant $(12 \pm 0.4)$ when they were cultured on MS supplemented with $3.0 \mathrm{mg} / \mathrm{l} \mathrm{Kn}$ and $0.5 \mathrm{mg} / \mathrm{l} \mathrm{NAA}$. Addition of $10 \% \mathrm{CW}$ to above mentioned medium increased the number of shoots (18) per culture. Shoot tip explants also produced multiple shoots in the same medium, but their performance was not good as leaf segment explants. For shoot elongation, 100 $\mathrm{mg} / \mathrm{l}$ urea was more effective when added with best shoot induction medium. Shoots rooted well in halfstrength MS supplemented with $2.0 \mathrm{mg} / \mathrm{l} \mathrm{NAA}$, within 12 - 15 days. Regenerated plantlets were successfully acclimatized and established in poly bag containing a mixture of soil and compost in 2:1 ratio. About $90 \%$ plantlets survived under open field conditions.
\end{abstract}

Paulownia tomentosa (Thunb.) Steud. is a very fast growing hard wood tree commonly known as Empress tree belongs to the family Paulowniaceae. It is not only ornamental tree but also a multi-purpose species and source of renewable energy. Paulownia tree is also used for paper pulp, electric poles, construction materials, plywood and furniture (Barton et al. 2007).

Now Paulownia is widely planted for the protection of environmental pollution, increase the soil texture, enhance the soil fertility by adding nitrogen in the soil and also reduce the soil erosion. Paulownia could be propagated by seeds and root cuttings (Rao et al. 1996, Ozaslan et al. 2005). Traditional methods of propagation through seeds are unreliable because of disease and pest problem, poor germination and also slow growth than cuttings (Bergmann and Moon 1997). But on the other hand in vitro technique has greatly enhanced the scope and potentiality of mass propagation by exploiting the regeneration behavior in a wide range of selected horticultural plants (Bajaj 1986, Bonga and Durjan 1987).

Many authors already reported the method of Paulownia micropropagation (Marcotrigiano and Stimart 1983, Venkateswarlu et al. 2001, Ipekci et al. 2001, Litwinezuk and Bochnia 2012, Burger et al. 1985, Rajbahak and Sah 2010, Taha et al. 2008). But their is no report regarding in vitro propagation of Paulownia tomentosa (Thunb.) Steud. in our country. Therefore, the importance of this woody plant and to overcome the problem of propagation through conventional method, attempt has been made to develop an efficient and reproducible regeneration protocol for clonal propagation of this plant.

For plant materials, shoot tips and young leaves were collected from field grown plants at Tongi, Gazipur, Dhaka. They were surface sterilized with aqueous solution of $0.1 \% \mathrm{HgCl}_{2}$ for six min under aseptic conditions in laminar air flow cabinet and rinsed four - five times with autoclaved distilled water to wash away the traces of $\mathrm{HgCl}_{2}$ completely. Before implanting onto the culture media they were cut into small pieces (approximately $1.0-1.5 \mathrm{~cm}$ in length). Shoot tip and leaf segment were cultured on MS supplemented with different concentrations of cytokinins 
(BAP, Kn, zeatin) and auxin (NAA) singly or in combination for shoot regeneration. Half-strength MS supplemented with auxin such as IBA, IAA and NAA were used for root formation. Media supplements such as coconut water $(\mathrm{CW})$ and urea were added to the medium for the determination of their effects on shoot multiplication and elongation, respectively. The cultures were regularly sub-cultured at three weeks intervals on fresh medium. For hardening, the test tubes containing rooted shoots were kept at room temperature and light for five days. Thereafter, the well rooted in vitro regenerated plantlets were taken out from the test tubes and gently washed to free the agar. They were then transplanted to poly bag containing a mixture of soil and compost in $2: 1$ ratio. After one month the plantlets were transferred to open field.

Explants were cultured on MS supplemented with different concentrations o BAP, Kn, zeatin and NAA alone or in various combinations for multiple shoot induction. In both shoot tip and leaf segment explants, the highest percentage of shoot proliferation was observed on MS supplemented with $3.0 \mathrm{mg} / \mathrm{l} \mathrm{Kn}$ and $0.5 \mathrm{mg} / \mathrm{l} \mathrm{NAA}$. In the case of shoot tips, $90 \%$ of cultures were found to regenerate shoots and the number of regenerated shoots per explant was $10 \pm 0.4$ on the above mentioned medium (Table 1, Fig. 1a). In the same medium, multiple shoots induction from the leaf segment explant was $12 \pm 0.4$ per culture (Table 1, Fig. 1b). After first subculture in the same medium, both shoot tip and leaf segment explants produced more shoots (Figs 1c, d).

Table 1. Effect of growth regulators in MS basal medium on shoot proliferation from shoot tip and leaf segment explants of Paulownia tomentosa. Data were taken after four weeks of culture.

\begin{tabular}{|c|c|c|c|c|}
\hline \multirow{2}{*}{$\begin{array}{c}\text { Growth regulators } \\
(\mathrm{mg} / \mathrm{l})\end{array}$} & \multicolumn{2}{|c|}{$\%$ of explants produced shoots } & \multicolumn{2}{|c|}{ Average number of shoots/culture } \\
\hline & Shoot tip & Leaf segment & Shoot tip \pm SE & Leaf segment $\pm \mathrm{SE}$ \\
\hline \multicolumn{5}{|l|}{ BAP } \\
\hline 1.0 & 78 & 70 & $7 \pm 0.4$ & $5 \pm 0.3$ \\
\hline 1.5 & 70 & 68 & $6 \pm 0.2$ & $4 \pm 0.2$ \\
\hline 2.0 & 64 & 60 & $6 \pm 0.2$ & $3 \pm 0.2$ \\
\hline \multicolumn{5}{|l|}{ Kn } \\
\hline 1.0 & 58 & 50 & $4 \pm 0.3$ & $5 \pm 0.3$ \\
\hline 1.5 & 60 & 52 & $4 \pm 0.2$ & $5 \pm 0.2$ \\
\hline 2.0 & 64 & 58 & $5 \pm 0.3$ & $6 \pm 0.3$ \\
\hline \multicolumn{5}{|l|}{ Zeatin } \\
\hline 1.0 & 44 & 40 & $4 \pm 0.2$ & - \\
\hline 1.5 & 50 & 44 & $5 \pm 0.3$ & - \\
\hline 2.0 & 48 & 40 & $3 \pm 0.2$ & - \\
\hline \multicolumn{5}{|l|}{$\mathbf{B A P + N A A}$} \\
\hline $1.0+0.1$ & 84 & 78 & $8 \pm 0.4$ & $10 \pm 0.4$ \\
\hline $1.5+0.1$ & 78 & 70 & $5 \pm 0.3$ & $6 \pm 0.3$ \\
\hline $2.0+0.1$ & 60 & 58 & $5 \pm 0.2$ & $5 \pm 0.3$ \\
\hline \multicolumn{5}{|l|}{ Kn + NAA } \\
\hline $1.0+0.5$ & 60 & 50 & $5 \pm 0.3$ & $6 \pm 0.3$ \\
\hline $2.0+0.5$ & 78 & 68 & $7 \pm 0.4$ & $8 \pm 0.3$ \\
\hline $3.0+0.5$ & 90 & 80 & $10 \pm 0.4$ & $12 \pm 0.4$ \\
\hline $3.5+0.5$ & 80 & 74 & $6 \pm 0.3$ & $6 \pm 0.2$ \\
\hline \multicolumn{5}{|l|}{ Zeatin + NAA } \\
\hline $1.0+0.5$ & 44 & 40 & $4 \pm 0.2$ & - \\
\hline $2.0+0.5$ & 58 & 54 & $5 \pm 0.2$ & $2 \pm 0.2$ \\
\hline
\end{tabular}

Ipekci et al. (2001) and Litwinczuk and Bochnia (2012) reported that MS medium supplemented with $1.0 \mathrm{mg} / \mathrm{l} \mathrm{BAP}$ and $0.1 \mathrm{mg} / \mathrm{l} \mathrm{NAA}$ was optimum to regenerate multiple shoots in Paulownia from shoot tip explant. Superiority of BAP over other cytokinins for multiple shoots formation in Paulownia has also been reported (Taha et al. 2008). 

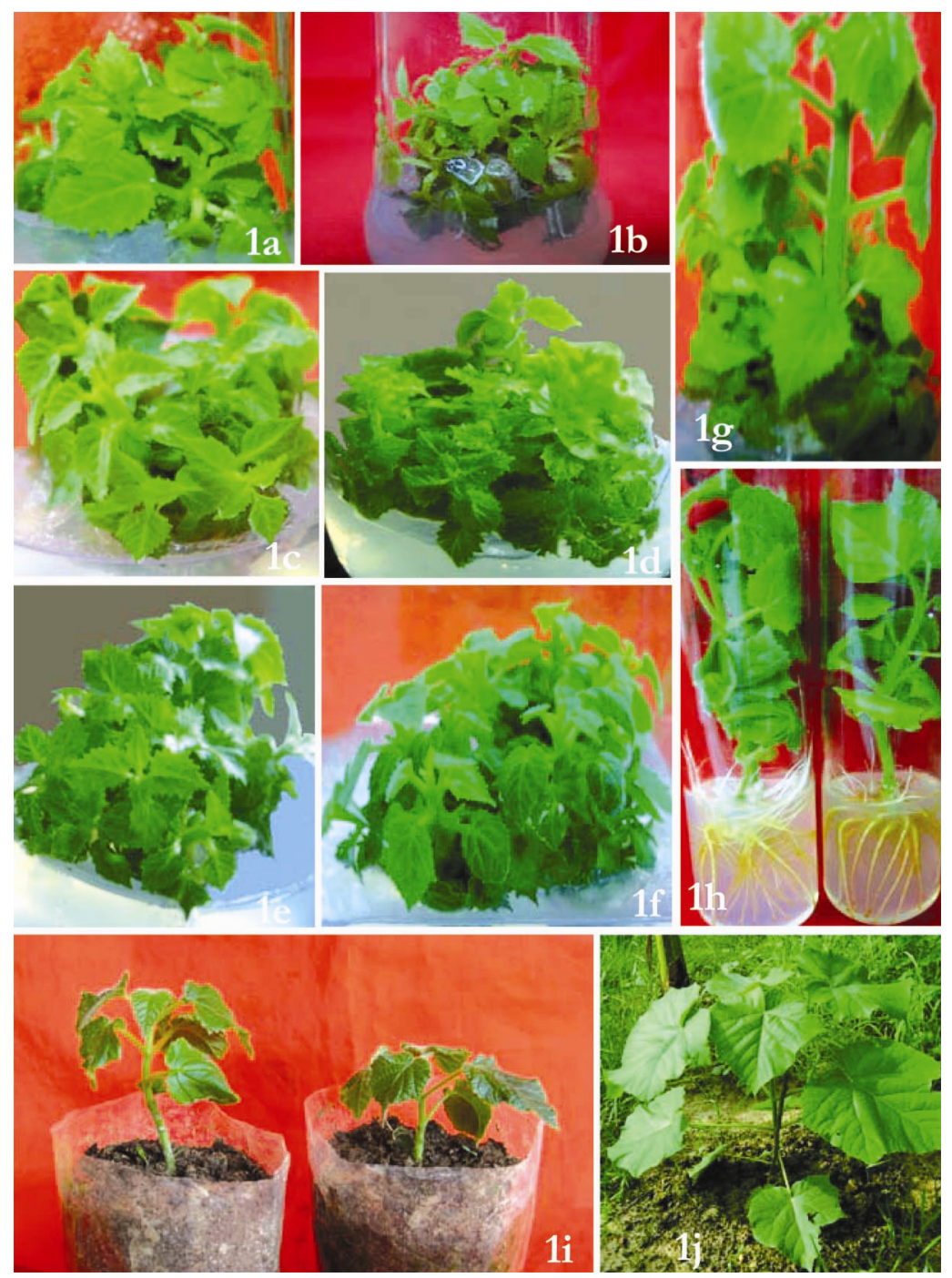

Figs 1a-j. In vitro regeneration of Paulownia tomentosa. a-b. Multiple shoot regeneration from shoot tip and leaf segment explant on MS supplemented with $3.0 \mathrm{mg} / \mathrm{l} \mathrm{Kn}$ and $0.5 \mathrm{mg} / \mathrm{l} \mathrm{NAA}$. c - d. More shoots after first subculture in the same medium. e - f. Positive effect of $10 \% \mathrm{CW}$ on increase the number of shoots in shoot tip explant and leaf segment explant. g. Effect of $100 \mathrm{mg} / \mathrm{l}$ urea on shoot elongation. $\mathrm{h}$. In vitro root induction on half-strength MS supplemented with $2.0 \mathrm{mg} / \mathrm{l}$ NAA. i. Regenerated plantlets in poly bag containing a mixture of soil and compost in $2: 1$ ratio. j. Survived plant in open field conditions.

For further development of the medium and enhanced shoot proliferation, coconut water $(\mathrm{CW}$ $5-20 \% \mathrm{v} / \mathrm{v}$ ) was added to the medium. Addition of $10 \% \mathrm{CW}$ increased the number of shoots (15 and 18 in case of shoot tip and leaf segment explant, respectively) per culture (Figs 1e, f). Different concentrations of urea $(50-150 \mathrm{mg} / \mathrm{l})$ were added to the medium to determination of their effects on shoot elongation. Addition of $100 \mathrm{mg} / \mathrm{l}$ urea to the medium increased the length of shoots (Figs 1g, 2). Roy (2008) reported that addition of $10 \% \mathrm{CW}$ increased the number of shoots 
in Boerhaavia diffusa L. culture. Rahman et al. (1999) also observed similar effects of CW (10\%) on in vitro shoot multiplication of Emblica officinalis. Minocha (1981) reported that urea was important media factor in the in vitro culture of Betula papyifera. Roy (2008) and Ahmed et al. (2001) also reported that urea was fruitful media supplement for in vitro shoot elongation.

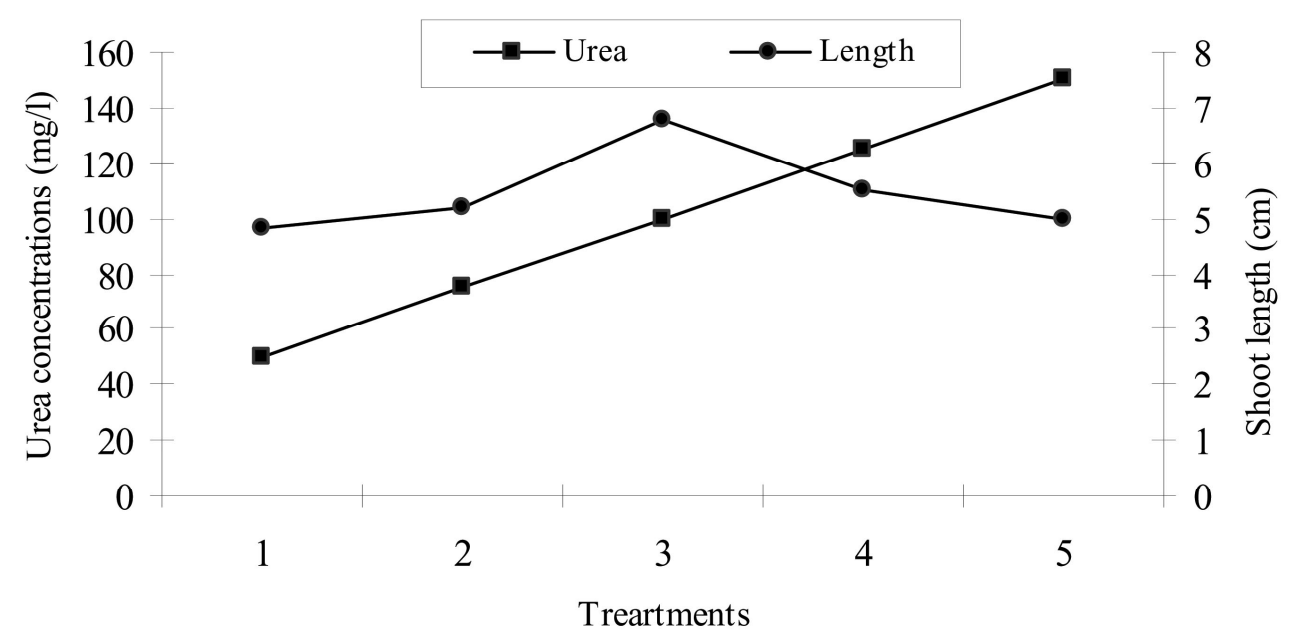

Fig. 2. Effect of different concentrations of urea $(50-150 \mathrm{mg} / \mathrm{l})$ along with $\mathrm{MS}+3.0 \mathrm{mg} / \mathrm{l} \mathrm{Kn}+0.5 \mathrm{mg} / \mathrm{l}$ NAA on shoot elongation.

Table 2. Effect of auxins in half-strength MS medium on root formation from regenerated shoots of Paulownia tomentosa. Data were taken after four weeks of culture.

\begin{tabular}{lcccc}
\hline $\begin{array}{l}\text { Auxins } \\
(\mathrm{mg} / \mathrm{l})\end{array}$ & $\begin{array}{c}\text { \% of shoots } \\
\text { rooted }\end{array}$ & $\begin{array}{c}\text { Days required for } \\
\text { rooting }\end{array}$ & $\begin{array}{c}\text { No. of roots per } \\
\text { shoots }\end{array}$ & $\begin{array}{c}\text { Average root } \\
\text { length }(\mathrm{cm} .)\end{array}$ \\
\hline IBA & & & & \\
1.0 & 84 & $15-18$ & $6-8$ & $3 \pm 0.2$ \\
1.5 & 80 & $15-18$ & $5-7$ & $3 \pm 0.2$ \\
2.0 & 80 & $18-20$ & $6-8$ & $4 \pm 0.3$ \\
IAA & & & & \\
1.0 & 48 & $18-20$ & $4-6$ & $2 \pm 0.3$ \\
1.5 & 60 & $18-20$ & $6-8$ & $3 \pm 0.2$ \\
2.0 & 54 & $20-22$ & $6-8$ & $3 \pm 0.2$ \\
NAA & & & & \\
1.0 & 90 & $14-16$ & $8-10$ & $4 \pm 0.2$ \\
1.5 & 88 & $16-18$ & $5-7$ & $4 \pm 0.3$ \\
$\mathbf{2 . 0}$ & $\mathbf{9 8}$ & $\mathbf{1 2 - 1 5}$ & $\mathbf{1 0 - 1 2}$ & $\mathbf{5} \pm \mathbf{0 . 3}$ \\
2.5 & 80 & $15-17$ & $6-8$ & $4 \pm 0.2$ \\
IBA+ IAA & & & & \\
$1.0+0.5$ & 68 & $18-20$ & $6-8$ & $3 \pm 0.3$ \\
$1.5+0.5$ & 50 & $20-22$ & $3-5$ & $2 \pm 0.2$ \\
NAA + IBA + IAA & & & & \\
$1.5+0.5+0.5$ & 68 & $15-17$ & $5-7$ & $3 \pm 0.2$ \\
$2.0+0.5+0.5$ & 74 & $16-18$ & $6-8$ & $4 \pm 0.3$ \\
\hline
\end{tabular}


For root induction, in vitro regenerated well-developed and elongated shoots were excised and cultured on rooting medium containing half-strength MS with different concentrations and combinations of IBA, IAA and NAA. The best result was obtained in half-strength MS supplemented with $2.0 \mathrm{mg} / \mathrm{l}$ NAA (Table 2). In this combination, it was observed that $98 \%$ shoots rooted well within four weeks of culture and each microcutting produced 10-12 roots (Fig. 1h). Taha et al. (2008) and Burger et al. (1985) reported that NAA was more effective for in vitro rooting of Paulownia. They observed that half-strength MS with $1.0 \mathrm{mg} / \mathrm{l} \mathrm{NAA}$ was suitable combination for best rooting, which is similar with my second highest result. For acclimatization and plant establishment under the natural conditions, the well rooted plantlets were transferred to poly bag containing a mixture of soil and compost in 2:1 ratio (Fig. 1i). After acclimatization, 90\% plantlets were survived in the open field. The results of the present investigation demonstrate a reproducible and efficient regeneration protocol of Paulownia tomentosa (Thunb.) Steud. through in vitro culture. The technique described here appears to be readily adaptable for large scale clonal propagation and plantation in the forest floor for sustainable uses.

\section{References}

Ahmed G, Roy PK and Mamun ANK 2001. High frequency shoot regeneration from nodal and shoot tip explants in Holarrhena antidysenterica L. Indian J. Experimental Biol. 39: 1322-1324.

Bajaj YPS 1986. Trees. In: Biotechnology in Agriculture and Forestry. Springer- Verlag, Berlin. p. 515.

Barton IL, Nicholas ID and Ecroyd CE 2007. Paulownia. The Forest Research Bull. 231: 5-68.

Bergmann BA and Moon HK 1997. In vitro adventitious shoot production in paulownia. Plant Cell Rep. 16: 315-319.

Bonga JM and Durzan DJ 1987. Cell and Tissue Culture in Forestry (Vols. 1,2,3). Martinus-nijhoff Publ. Dordrecht.

Burger DW, Liu L and Wu L 1985. Rapid micropropagation of Paulownia tomentosa. Hort. Sci. 20: 760-764.

Ipekci Z, Altinkut A, kazan K, Bajrovic K and Gozukirmizi N 2001. High frequency plant regeneration from nodal explants of Paulownia elongata. Plant Biol. 3(2): 113-11.

Litwinczuk W and Bochnia E 2012. Development of royal paulownia ( Paulownia tomentosa Steud.) in vitro shoot cultures under the influence of different saccharides. Acta Sci. Pol., Hortorum Cultus 11(2): 3-13.

Marcotrigiano M and Stimart DP 1983. In vitro organogenesis and shoot proliferation of Paulownia tomentosa Steud. ( Empress tree). Plant Sci. Lett. 31(2-3): 300-310.

Minocha SC 1981. Role of the source of nitrogen in the growth of shoot tip and callus cultures of woody plant in vitro. In: IUFRO. Sect. S2015. Int. Workshop on In vitro Culture of Forest Tree species. Fontainbleau, France. pp. 227-235.

Ozaslan M, Can C and Aytekin T 2005. Effect of explant source on in vitro propagation of Paulownia tomentosa Steud. Biotechnol. \& Biotech. Equipment 19: 20-26.

Rahman MM, Roy PK, Mannan MA and Roy SK 1999. Clonal propagation of Emblica officinalis through in vitro culture. Plant Tissue Cult. 9(1): 17-23.

Rajbahak S and Sah SK 2010. Micropropagation of Paulownia tomentosa through in vitro culture technique. St. Xavier's J. Sci. 2(1): 15-20.

Rao C, Goh C and Kumar PP 1996. High frequency adventitious shoot regeneration from excised leaves of Paulownia spp. cultured in vitro. Plant Cell Rep. 16: 204-209.

Roy PK 2008. Rapid multiplication of Boerhaavia diffusa L. through in vitro culture of shoot tip and nodal explant. Plant Tissue Cult. \& Biotech. 18(1): 49-56.

Taha LS, Soad Ibrahim MM, Farahat MM 2008. A micropropagation of Paulownia kowa-kami through in vitro culture technique. Austral. J. Basic and Appl. Sci. 2(3): 594-600.

Venkateswarlu B, Mukhopadhyay J, Sreenivasan E and Kumar VM 2001. Micropropagation of Paulownia fortuneii through in vitro axillary shoot proliferation. Indian J. Experimental Biol. 39(6): 594-599. 